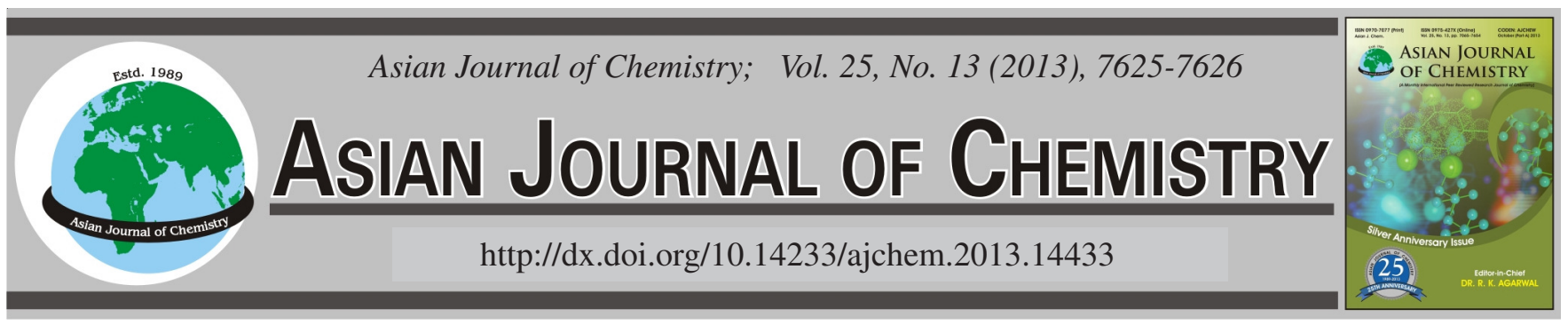

NOTE

\title{
Simultaneously Determining the Wholesome and Harmful Elements in Wild Amaranthus mangostanus L. by ICP-MS
}

\author{
LinJiang PAng ${ }^{1, *}$, Xinghua Lu ${ }^{2}$ and YunXIANG WANG ${ }^{1}$
}

${ }^{1}$ School of Agriculture and Food Science, Zhejiang A \& F University, Hangzhou 311300, P.R. China

${ }^{2}$ Department of Biology and Environment, Zhejiang A \& F University, Hangzhou 311300, P.R. China

*Corresponding author: Tel: +86 571 63748155; E-mail: pang_linjiang@163.com

(Received: 14 August 2012;

Accepted: 5 July 2013)

AJC-13766

\begin{abstract}
In this study, the contents of many trace elements were simultaneously determined in wild Amaranthus mangostanus L. by ICP-MS. The results showed that Amaranthus mangostanus L. contained many kinds of wholesome elements, especially $\mathrm{K}, \mathrm{Ca}$ and $\mathrm{Mg}$ were all more than $2000 \mu \mathrm{g} / \mathrm{g} \mathrm{FW}$. The concentration of Fe in Amaranthus mangostanus L. was $53.36 \mu \mathrm{g} / \mathrm{g} \mathrm{FW}$, which should be the reason why Amaranthus mangostanus L. have therapeutic efficacy for iron deficiency anemia. The descending order of the other wholesome is Na $>$ $\mathrm{Zn}>\mathrm{Sr}>\mathrm{Mn}>\mathrm{Cu}>\mathrm{Mo}>\mathrm{Li}>\mathrm{Se}$. As, $\mathrm{Cr}$ and $\mathrm{Cd}$ in Amaranthus mangostanus $\mathrm{L}$. did not exceeded the national standard, but the concentration of lead was higher than the national standard, so wild Amaranthus mangostanus L. should be detected before eating.
\end{abstract}

Key Words: Amaranthus mangostanus L., Wholesome elements, Harmful elements, ICP-MS.

ᄂ - - - - - - - - - - - - - - - - - - - - - - - - -

Amaranth (Amaranthus mangostanus L.) is annual herb, which belongs to Amaranthaceae, whose edible organs are tender leaves and stems. Amaranth were distributed around the world. In recent years, with the quest for a return to nature, wild amaranth becomes essential vegetables of people on the table and upscale hotels. Amaranth contains a wealth of essential nutrients, such as carotene, vitamin $B_{1}$, vitamin $B_{2}$, vitamin $\mathrm{C}$ and trace elements $\mathrm{Ca}$ and $\mathrm{Fe}$. All parts of amaranth plant can be used as medicine, which have therapeutic efficacy for enteritis, constipation, goiter, iron deficiency anemia, jaundice and cancer. But the mechanism for the above-mentioned efficacy of amaranth is less reported, especially the main active ingredients in amaranth is not comprehensively reported and content of harmful elements has not been reported. It is of great significance to find these functions of amaranth to study the contents of more trace elements ${ }^{1}$.

Trace elements, as the body of vital nutrients, are essential for human health. Several trace elements ( $\mathrm{Ca}$ and $\mathrm{Fe}$ ) has been studied in amaranth, which is not enough to study nutrition and the mechanism of therapeutic efficacy of amaranth. With the development of instrumental analysis techniques, determination of trace elements becomes more and more simple and more and more accurate. Inductively coupled plasma mass spectrometry (ICP-MS) is good technology developed in recent years for determination of trace elements ${ }^{2}$. In addition to the accuracy and efficiency, ICP-MS can also determine many elements simultaneously.

All trace elements in Amaranthus mangostanus L. were determined by inductively coupled plasma mass spectrometry (ICP-MS, Model Thermo-X7, Thermo Electron Corporation, USA).

The wild Amaranthus mangostanus L. (Fig. 1) were collected from Mount Tianmu, Hangzhou District of Zhejiang province, China. Samples were taken back to the laboratory in the incubator in order to avoid water loss.

Weighing $0.5 \mathrm{~g}$ Amaranthus mangostanus L. in a mortar to grind into the homogenate and add $6 \mathrm{~mL}$ of concentrated nitric acid soaking for $12 \mathrm{~h}$, then add $2 \mathrm{~mL} 30 \% \mathrm{H}_{2} \mathrm{O}_{2}$ solution soaking for $4 \mathrm{~h}$; digesting and heating to boiling of the sample until remaining $1 \mathrm{~mL}$, transferring to a $15 \mathrm{~mL}$ centrifuge tube. Constant volume to $10 \mathrm{~mL}$. Experiment was repeated 5 times.

Parameters of ICP: Power, $1200 \mathrm{~W}$; flow of cooling gas (Ar), 12.0 L/min; flow of supplemental gas (Ar), $1.80 \mathrm{~L} / \mathrm{min}$; flow of carried gas (Ar), $0.90 \mathrm{~L} / \mathrm{min}$. Parameters of MS: vaccum of analysis room, $5.86 \times 10-6$ Torr; impulse voltage, $1150 \mathrm{~V}$

Wholesome elements in Amaranthus mangostanus L.: The results showed that Amaranthus mangostanus L. contains 


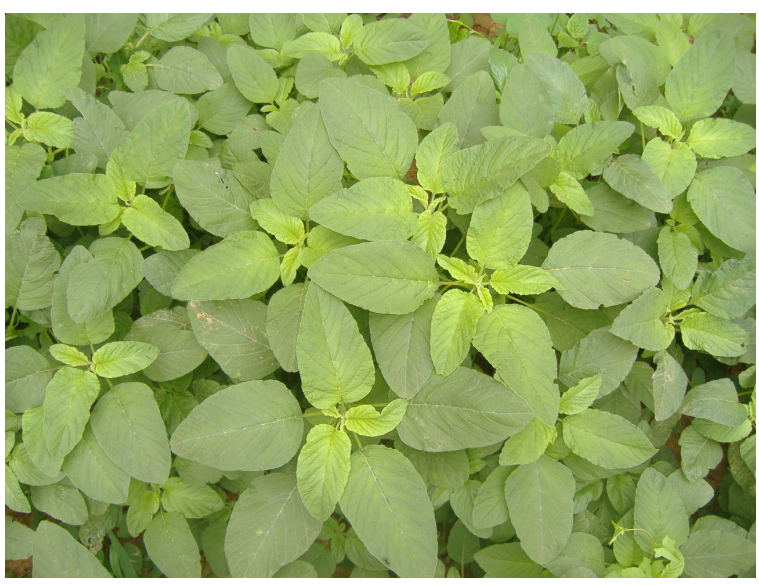

Fig. 1. The wild Amaranthus mangostanus L.

many kinds of wholesome elements, especially $\mathrm{K}, \mathrm{Ca}$ and $\mathrm{Mg}$, whose concentrations were all higher than $2000 \mu \mathrm{g} / \mathrm{g}$ FW. The concentration of Fe in Amaranthus mangostanus L. was 53.36 $\mu \mathrm{g} / \mathrm{g}$ FW, which should be the reason why Amaranthus mangostanus L. have therapeutic efficacy for iron deficiency anemia. The descending order of the other wholesome is $\mathrm{Na}>$ $\mathrm{Zn}>\mathrm{Sr}>\mathrm{Mn}>\mathrm{Cu}>\mathrm{Mo}>\mathrm{Li}>\mathrm{Se}($ Table-1).

TABLE-1

CONTENTS OF WHOLESOME ELEMENTS

IN WILD Amaranthus mang ostanus $L$.

\begin{tabular}{cr}
\hline Elements & \multicolumn{1}{c}{ Content } \\
\hline $\mathrm{Li}$ & $61.56 \mathrm{ng} / \mathrm{g} \mathrm{FW}$ \\
$\mathrm{Fe}$ & $53.36 \mu \mathrm{g} / \mathrm{g} \mathrm{FW}$ \\
$\mathrm{K}$ & $8359.20 \mu \mathrm{g} / \mathrm{g} \mathrm{FW}$ \\
$\mathrm{Mg}$ & $2277.69 \mu \mathrm{g} / \mathrm{g} \mathrm{FW}$ \\
$\mathrm{Na}$ & $19.26 \mu \mathrm{g} / \mathrm{g} \mathrm{FW}$ \\
$\mathrm{Zn}$ & $15.14 \mu \mathrm{g} / \mathrm{g} \mathrm{FW}$ \\
$\mathrm{Se}$ & $15.87 \mathrm{ng} / \mathrm{g} \mathrm{FW}$ \\
$\mathrm{Mo}$ & $401.53 \mathrm{ng} / \mathrm{g} \mathrm{FW}$ \\
$\mathrm{Sr}$ & $11.71 \mu \mathrm{g} / \mathrm{g} \mathrm{FW}$ \\
$\mathrm{Cu}$ & $2.27 \mu \mathrm{g} / \mathrm{g} \mathrm{FW}$ \\
$\mathrm{Mn}$ & $8.13 \mu \mathrm{g} / \mathrm{g} \mathrm{FW}$ \\
\hline
\end{tabular}

Harmful elements in Amaranthus mangostanus L.: Harmful metals mainly refers to heavy metals, including As, $\mathrm{Cr}, \mathrm{Cd}$ and $\mathrm{Pb}$, which is important to evaluate the food safety. The data showed that $\mathrm{As}, \mathrm{Cr}, \mathrm{Cd}$ and $\mathrm{Pb}$ in Amaranthus mangostanus L. were 27.95, 81.24, 19.60 and $235.12 \mathrm{ng} / \mathrm{g}$ FW respectively (Table-2). As, $\mathrm{Cr}$ and $\mathrm{Cd}$ in Amaranthus mangostanus L. did not exceeded the national standard ${ }^{3-5}$, but the concentration of $\mathrm{Pb}$ was higher than the national standard ${ }^{6}$, which should be relative to the soil and groundwater. So wild Amaranthus mangostanus L. should be detected before eating.

\begin{tabular}{cc} 
TABLE-2 \\
CONTENTS OF HARMFUL ELEMENTS IN \\
WILD Amaranthus mangastanus L. (ng/g FW) \\
\hline Elements & Content \\
\hline As & 27.95 \\
$\mathrm{Cd}$ & 19.60 \\
$\mathrm{~Pb}$ & 235.12 \\
$\mathrm{Cr}$ & 81.24 \\
\hline
\end{tabular}

\section{ACKNOWLEDGEMENTS}

The authors acknowledged the financial support of Natural Science Foundation of Zhejiang province through Project LQ12C15001, Education Department of Zhejiang Province through Project Y201018202.

\section{REFERENCES}

1. H.-L. Fan and W. Zhou, Agric. Sci. China, 8, 342 (2009).

2. S. Tokalioglu, Food Chem., 134, 2504 (2012)

3. National Standard of the People's Republic of China, Tolerance Limit of Chromium in Foods, No. GB 14961-94.

4. National Standard of the People's Republic of China, Tolerance Limit of Cadmium in Foods, No. GB 15201-94.

5. National Standard of the People's Republic of China, Tolerance Limit of Arsenic in Foods, No. GB 4810-94.

6. National Standard of the People's Republic of China, Tolerance Limit of Lead in Foods, No. GB 14935-94. 